\title{
The Innovation and Its Driving Power of Modern Football's Technical Aspects in Development
}

\author{
Songhengmao \\ Department of physical education of Jiangsu Zhenjiang \\ city, Jiangsu Province, China \\ 87516235@qq.com
}

\author{
xucaiyan \\ Department of physical education of Jiangsu Zhenjiang \\ city, Jiangsu Province, China \\ Ntyzzj2004@163.com
}

\begin{abstract}
Technique is one of the four basic elements of the modern soccer. In the process of the development of soccer ,the technique has most innovations. The conflict between attack and defense, the revision of the formation and tactics, the continual modification of the competition rules ,the intenser confrontation of the competition, the ever-growing difficulty of technique application, the all-round development of the attackdefense ability of players and the high-speed development of the innovation and development technique.
\end{abstract}

Keywords- modern soccer, technique segment, development and innovation, motivation Introduction

Up to date, the modern football has been developed for over 140 years in sports' history. In the process of its development, great changes have taken place in the field, such as the technical, tactical, offensive, defensive sectors and so on. In those links, technology is the most innovative aspects. Especially since the 1950s, with the deepening understanding of football activities, the law of the development of football skills was so gradually revealed that the football technology has been developed rapidly.

\section{THE DEVELOPMENT AND INNOVATION OF FOOTBALL SKILLS}

Not only the impact of venues and equipment but also the tactics, physical fitness, mental, football rules will restrict the evolution of football technology. And today's football skills have been developed from the most junior to a higher level, which have become even more complex not only in technical contact forms, but in its structures as well. The football skills functions have been better developed and turned into today's football skills system.

With the development of football, such as match formation and evolution of the tactical contest, rules modification, upgrading of venues and equipment, people at the same time innovated some football skills. The development of football skills shows that, once a team creates a certain kind of technology, there will be a lot of players followed imitation, therefore, to a certain extent, it has promoted a new kind of technology development. While they are mastering some kind of football skills to create, the athletes are also showing the different characteristics of the football skills at the same time. It is based on this that gave the new space for development of football skills. But the athletes have different personal characteristics in many aspects such as the talent, body shape, movement qualities, Each of the athletes also has individual differences in mastering football skills. For each of the athletes, the most reasonable skill will not exactly be the same, which has distinctive personal characteristics.

Dated from 1950s \& 1960s, the development of the football skills was widely recognized. I believe that football skills development is mainly manifested in the following aspects:

- $\quad$ More and more football skills have been developed.

- There is the same function in different skills.

- To simplify the use of the football skills is another important aspect of the development. With accelerating the pace of modern football game, snatching viciously, it give athletes shorter and shorter time to complete the action in the game. So the space is getting smaller and smaller. In order to improve the rationality and adaptability to use football skills, it will inevitably go toward fast, concise, practical, accurate direction.

- To use a combination of different skills is an important trend in the development of football skills. The so-called skill portfolio is to use a single wellknown skill to make the different skills generate all new tuples and permutations according to the changing needs of the game so as to have a new structure, giving it a new function.

\section{THE EXAMPLES OF TECHNOLOGICAL INNOVATION RELATED TO FOOTBALL}

In the development of modern football, in addition to some of the basic techniques, there created some new and unique technologies, such as, deciduous ball, curving ball (or a banana kick), overhead kick, stepovers, diving header technology, etc.

\section{A. deciduous ball}

While kicking the central part of the football, it will be flying in one direction and suddenly sinking near the goal, just like a dead leaf falling from a tree, which is known as deciduous ball. It gives us the overall feeling that the ball in the air is almost not rotating, having it both ways, suddenly falling.

The deciduous ball technology is a method of shooting free kick. This shot technology can make goalkeeper misjudge the flying ball which can be leaded to goals. Its inventor is Dede, a Brazilian player, while the world famous deciduous ball experts is Albertini, a former AC Milan 
player; Andrea Pirlo, an active duty AC Milan player and CRonaldo, one of Mancheste $r$ United players.

\section{B. Curving ball (or a banana kick)}

You must have seen the wonderful scene: Closed to the opponents' goal on penalty kick directly, five or six people of the defending team will stand in a line as an adult wall in an attempt to block the scored-goal line, while the kick player puts the ball in straight position, and then gives a fierce shot, the ball around the wall threatens to deviate from the goal flying out of bounds, but turned the corner to directly toward the goal. The goalkeeper is difficult to judge. Because the running route of the ball is curved, like a banana shape, so it is called the "curving ball (or a banana kick) ".

The curving ball (or a banana kick) technology is a combination of speed, rotation and arc, which is an effective weapon with a fatal blow in the game. Beckham, Ronaldinho, Roberto Carlos, Juninho, Mihajlovic are masters who kick curving balls.

\section{Stepovers}

Stepovers is to use your feet around the ball constantly fast cruising feint, while two foot turns over the ball a step to a step to go, confusing other side to achieve a breakthrough in particular. This technique is easy to master, and was first used by several players in Brazil. The classic dribbling master is Denilson, and now high skilled master are Ronaldinho, C. Ronaldo and Robinho.

\section{Overhead kick}

Overhead kick refers to the body recline while playing, hooking the ball over his head backward kick. Overhead kick is an unconventional shot in the football game, on which you cannot often see. However, Overhead kick goals are often critical scores.

\section{E. Diving header}

Diving header is to push oneself human serve prone position to the ball at waist height, far away from the body. Other actions have been difficult to reach the ball and jumped to head the ball forward process due to heading the ball like a fish leap in general, so it is called a diving header. This technique is used for cutting in for goal, or shoot-on sight tactics for the ball to keep goal in front of the wreck.

\section{THE INNOVATIVE POWER OF THE DEVELOPMENT OF FOOTBALL SKILLS}

\section{A. Offense and defense confrontations}

Offensing and defensing confrontations is to promote the development of football skills. Football game goal is not to let the other ball scored their own goal, while doing everything possible to try to hack into the opponents' goal. This is the Master of the football skills. To achieve this master plan, you must firmly grasp the possession. Meanwhile the use of various technologies will also focus on this purpose. In the confrontation competing for the ball, the ball party must attack to achieve control of the ball by technical means, while defensive party is bound to use the effective defensive technical means to block the opponent's attack to regain possession, organizing to attack. Therefore, football offensive and defensive techniques have been developed in this contradictory offensive and defensive confrontation.

\section{B. The evolution of the game formation and tactics}

The people's awareness and understanding to the football always continue to deepen and improve. Game formation and the evolution of tactics is people's understanding of the nature of football. "Nine front a guard" system made the corresponding reckless breaking-ball technology; The formation of 235 made offensive and defensive forces to achieve such a balance for the first time that passing the ball, heading the ball, and dribbling skills emerged as the times require. It is visible that game formation and tactics change, to some extent, also promote the emergence of a variety of football skills.

\section{Constant revision of the rules of the game}

The revision of football competition rules has a great effect on its skill. For example, in the red and yellow card foul penalty, there is a high demand on players on the rational use of the technique in the competition. In order to avoid the yellow card's warn or the red card penalty which make the player be sent off, the athletes must have their own actions carved with special care, in order to improve the reasonableness and accuracy of the technology and to make the defense technology developed and perfect.

\section{The game is becoming increasingly fierce and technology use more difficult}

According to statistics, there is about 65 minutes of pure time in a game, in which the two sides fighting for more than 300 times. Confrontation contact happened once at an average of about 10 seconds. With the speed significantly accelerated in modern football game, the offensive and defensive confrontations are increasingly fierce and the players spent less and less time completing their technical movements in the game. The space is getting smaller and smaller. In order to adapt to the fierce competitive environment in the game, players must continue to improve the ability of the rational and effective use of technology, especially the players must have the ability to complete the speed of a single action, the interface between the technical movements and technical movements in the fast-running. It is of most significance to improve this ability to gain the initiative in the game thereafter.

\section{E. All-round development of the technical ability of the athletes' offense and defense}

Today's football skills is being developed toward the direction with a comprehensive, fast, skilled, concise, strong antagonistic offensive combination technique. Especially since the 10th World Cup Football Game was held in 1974, the football game has put forward higher requirements on the comprehensiveness of the players. Each of the players who is charged with the dual task of offense and defense, must have 
completed control of the offensive and defensive technology to meet the needs of the tactical changes and match. Especially in recent decades, either a comprehensive overall or a comprehensive person has continuously developed his abilities. Based on the need of position or personal expertise, the players are required to develop their expertise or excellent techniques through general mastery in an overall skill. As a football field all-rounder, the player is an expert either on personal characteristics or in a location. With the machinery division of the front and guard's labor disappeared, the defender drove straight down to assist attacking actions. Free defender thrust forth into the hinterland to organize offensive and goalkeeper stepped forward to long-range score, indicating that neither the defender nor the goalkeeper has only defensive role, while striker not only has a full set of offensive skills, but good grasp of the defensive skills such as grab, broken, shovel as well. In addition, the players have to adapt to the needs of the modern football game and their technical actions must also be diversified. On the basis of an overall technique, they should train their own specialty (trick) so as to play a multiplier role in the game.

\section{F. The rapid development of modern science and technology}

The development of modern science and technology has led to the further development of football. Modern science and technology has penetrated into all aspects of football. Football has been combined constantly with the high-tech process. It is of important practical significance to improve the athletes' upgrading skills. In 1986, football material was tremendously changed. Soccer used the synthetic material which is waterproof for the first time. In the high-tech era, we made it easy is to kick football better. With the development of high-tech, soccer has become more waterproof, more flexible, faster, more rounded or seamless, and of better flexibility so that athletes can get the ball well controlled to play football at a faster speed, passing the ball more accurately. The game was in a faster pace. Free kick chances were higher. Place kick was more threatening to score the goal. So the various lines of strange ball can be played out.

\section{CONCLUSION}

Football is a technology-dominated sport. The reason why the collective ball game has so much charm is mainly because of "technical experts"-players who grasp the extraordinary technology. In order to adapt to the needs of the modern football game, the players must remain the technology who have mastered, but also need to focus on learning a new technology. While constantly emphasized physical strength, speed and tactical changes, the necessary technology has been regarded as the premise in modern football game. With the speed of offensive and defensive accelerated in modern football game, the confrontation was increasingly fierce, and it proposed a new and higher requirement on football skills, which also provides a broad space for the development of football skills. Of course, today's football technical system is not perfect, with the further development of football, remains to be further supplemented, making it perfect.

[1] Wu, zhaoxiang. Sports Football encyclopedia encyclopedia [m]. people's sports publishing house, August 1998 first edition.

[2] Wang Chongxi. sports: football [m]. higher education press, July 2005 first edition

[3] (Germany) Karath the translation of Zhang Huanan. football skills and tactics [m]. people's sports publishing house, in May 2003 the first edition

[4] He Zhilin. modern football [m]. Higher education press, first edition in June 2000.

[5] Ma Xuetian. advanced course for modern football [m]. Higher education press, 2002

[6] Yang Yimin. Chinese sports coach post training materials [m]. Beijing sports University Press, 1997.

[7] He ziai. diversified thinking of scientific research [j]. oil and gas geology, 2000 (2): 180-1841

[8] Jianping $\mathrm{Xu}$. on the essence of creative thinking [j]. Journal of Shaanxi Normal University, 1999 (2): 161-166.

[9] Fuzhihua. development of our branch of the research team and study on the relationship between science and technology innovation [j]. Journal of Wuhan Institute of physical education, 2004 (1): 154-157

[10] Jing after Peng, zhe-Ming Ma. innovative core-thinking of the theory of innovation for the information society [j]. intelligence science 2004 (7): 769-763. 